In this article, the authors propose to model the influence of occupational structure on the sex-typing of occupational choice within a log-linear model framework. A key feature of the framework is that the explanatory variables vary as a function both of individual attributes and of choice attributes. The authors show how information about the structure of the labor force and the experiences of its male and female incumbents affect the occupational preferences of individuals early in the life course. Analyzing data on high school students in 1972 and 1979, the authors explore the influence of gender inequality in the societal makeup of the labor force through three hypothesized channels: (1) the extent of sex segregation of occupations in the labor force (the reflection model), (2) cross-occupational variation in pay equity between female and male workers (the expectation model), and (3) sex differences in the proportions of highly successful and unsuccessful workers (the reference model).

\title{
Modeling the Sex-Typing of Occupational Choice
} Influences of Occupational Structure

\author{
YU XIE \\ University of Michigan \\ KIMBERLEE A. SHAUMAN \\ University of California, Davis
}

$\mathbf{A}$

lthough human capital theory continues to be the dominant theoretical framework among economic analyses of the sex segregation of occupational choice, it has been the subject of harsh but healthy criticism for some time. First of all, the human capital framework rests on the assumption that individuals have complete freedom to make rational choices about their occupation. In the words

\footnotetext{
AUTHORS' NOTE: This research was supported by a research grant and a Young Investigator Award from the National Science Foundation, a Spencer Fellowship from the National Academy of Education, a Faculty Grant/Fellowship from the University of Michigan Rackham School of Graduate Studies to Yu Xie, and a National Institute of Child Health and Human Development (NICHD) traineeship to Kimberlee Shauman. We are grateful to Mark Becker, Chris Bettinger, John Bound, Scott Eliason, Emily Hannum, Richard Lempert, Margaret Marini, James Shockey, Howard Schuman, and
} 
of Blau and Jusenius (1976), it does not acknowledge or account for "the constraints imposed by society which limit women's freedom to make their own decisions" (p. 187). Further, given the assumption of freedom of choice, the human capital framework sweeps the residual gender differences in occupational choice unexplained by human capital variables under the catch-all rubric "taste." Gender differences in tastes, however, remain a black box in the human capital theory of occupational choice: Although human capital theory recognizes the relevance of tastes to occupational choice, it does not specify how gender differences in occupational tastes are produced. Finally, it thus far has failed to explicitly acknowledge the role of the occupational structure in the formation of gender-specific occupational tastes.

In this article, we address these criticisms by developing models of the influence of occupational structure on the sex-typing of occupational choice: Young men and women form preferences for certain occupations long before they actually enter the labor force, and their preference formation is affected by sex-linked characteristics of the labor force. We show how information about the structure of the labor force and the experiences of its male and female incumbents affect the occupational preferences of individuals early in the life course. To accomplish this, we analyze the effects of aggregate-level characteristics of the labor force on the occupational choices of high school students in 1972 and 1979. Specifically, we explore the influence of gender inequality in the societal makeup of the labor force on youth's desires to train for and enter particular occupations through three hypothesized channels: (1) the extent of sex segregation of occupations in the labor force (the reflection model), (2) cross-occupational variation in pay equity between female and male workers (the expectation model), and (3) sex differences in the proportions of highly successful and unsuccessful workers (the reference model). Drawing on psychological, economic, and sociological literature, the three

\footnotetext{
Michael Sobel for advice and comments on earlier drafts of this article. We also thank Charles Manski for providing the initial stimulus to this research through his work and personal communications. An earlier version of this article was presented at the 1992 Population Association of America annual meeting in a session organized and chaired by Clifford Clogg. Address correspondence to Yu Xie, Department of Sociology, University of Michigan, Ann Arbor, MI 48109-1382, or to Kimberlee Shauman, Department of Sociology, University of California, Davis, Davis, CA 95616.
} 
theoretical models have distinct implications for how gender stratification in the adult labor force affects youth's occupational choices, and these implications are tested against data from a nationally representative survey of high school seniors in 1972 and from the 1970 U.S. census. We further corroborate our findings with comparable data extracted from a national survey of youth in 1979 and the 1977-1979 March Current Population Surveys.

Our models are applications of the conditional logit model first developed by McFadden (1974), in which choices are modeled as a function of the characteristics of the individual chooser as well as the characteristics of the alternatives among which the individual chooses. Breen (1994) demonstrated the utility of this approach for the study of mobility tables by illustrating how the conditional logit model can be used to incorporate the effects of continuous variables into the log-linear models traditionally used to analyze tabular data. In this article, we apply the conditional logit methodology to the study of occupational choice to illuminate a neglected aspect of theories of sex segregation in occupational choice: the socialization of tastes.

\section{SOCIALIZATION AND OCCUPATIONAL PREFERENCES}

Departing from economic research that infers revealed preferences from actual behavior of adult workers, we directly model stated preferences of youth. The value of modeling stated preferences is underscored by the criticisms of the human capital model of occupational choice: Understanding the social processes that produce occupational preferences or tastes is essential to understanding occupational segregation in the adult labor force. Unlike revealed preferences, stated occupational preferences of high school students exist prior to the influence of economic and other structural forces that sort men and women into different occupational categories, and stated preferences are relatively free of the effects of personal experiences in the labor force (such as sex discrimination). At this point in the life course, hence, occupational choice is a purer indicator of socialized tastes. In contrast, studies of the revealed occupational choices of adults confound the effects of socialized preferences with experiential, economic, and structural influences. 
The complex process by which occupational preferences are socialized is the topic of large bodies of sociological and psychological research. The socialization mechanisms proposed in the literature, however, have proven rather limited for the explanation of how individuals come to prefer or choose certain occupational roles. They tend to focus on individual-level influences and neglect the influence of gender stereotyping that pervades the social structure. Based on an extension of role model theory, we develop models that specify the influence of the social structure on individual occupational choices of high school students. Our theoretical framework emphasizes that individuals are not impassive receptors of the information they receive from the social structure. Instead, individuals assess the information and use it as the basis for rational decisions. We will show that the information about the occupational structure, albeit abstract and incomplete, nonetheless influences the occupational choices of youth before they gain firsthand experience in the labor force.

Our basic thesis is that the U.S. occupational structure affects high school students' perceptions of the gender appropriateness and accessibility of various occupations. In contrast to classical reference group theory (Merton 1968, chaps. 10 and 11), which views one's peers as role models, our theoretical model posits that for the occupational choice problem, role models should be persons actually working in the labor force (see also Manski 1993). Youth learn from the experiences of their advanced peers - that is, their role models. As an earlier study (Gaeddert et al. 1981) found, the choice of role models is almost uniformly sex linked: Females almost always choose other females, and males almost always choose other males, as role models. Thus, in this study, we are interested in how sex-linked characteristics of the occupational structure affect the sex-typing of youth's occupational choices. Drawing on theories in psychology, economics, and sociology, we develop three theoretical models specifying three distinct mechanisms through which the structure of the labor force influences occupational preferences-that is, how preferences for occupational roles are modeled on the existing occupational structure.

An assumption that underlies this study is that youth make occupational choices consciously on the basis of adult workers' experiences, at the aggregate level, in the labor force. Young women project their future career outcomes from female workers' experiences, and young 
men project their future career outcomes from male workers' experiences. This departs radically from the Wisconsin model (Sewell, Haller, and Portes 1969; Sewell and Hauser 1975; Hauser, Tsai, and Sewell 1983), which emphasizes the influences of significant others (peers, teachers, and parents) on youth's educational and occupational aspirations. Although it is true that high school students affect each others' occupational choices, as predicted by the Wisconsin model, this type of influence works predominantly indirectly, by transmitting information about the labor market to individual students, because youth lack extensive direct experiences in the labor market. In addition, teachers and parents influence youth primarily as information providers and only secondarily as role models in particular occupations (Laska and Micklin 1979). Thus, youth's knowledge of specific occupations comes from the labor market as a whole. Peers, teachers, and parents exert immediate influence on students' occupational choices, but the content of the influence is ultimately derived from the experiences of adult workers. In the language of structural equation models, our research design is one of finding the total effects of labor force characteristics on youth's occupational choices.

\section{THE MODELS}

In this section, we introduce three theoretical models that are operationalized within the log-linear model framework. ${ }^{1}$ Each of the three theoretical models describes a specific and distinct mechanism through which the structure of the occupational labor force affects sex differences in youth's occupational choices. The log-linear models are identical to McFadden's (1974) conditional logit model (also called the discrete choice model). The key feature of the models is that the explanatory variables vary as a function both of individual attributes (i.e., gender in our study) and of choice attributes (i.e., occupation in our study).

\section{INDEPENDENCE MODEL}

We begin with the naive baseline model that there is no sex-typing of occupational choice-that is, occupational choice and sex are 
independent of each other. This is the baseline model against which to compare the three theoretical models. For the contingency table of sex by occupational choice, let $f_{i j}$ denote the observed frequency for the $i$ th sex ( $i=1$ for male, 2 for female) and the $j$ th occupation $(j=1, \ldots, J)$, where $J$ is the number of occupational categories. Under some model, $f_{i j}$ has expectation $F_{i j}$. The independence model can be written as

$$
\log \left(F_{i j}\right)=\gamma_{i}+\alpha_{j}=\delta \operatorname{SEX}_{i}+\alpha_{j},
$$

where $\gamma_{i}$ and $\alpha_{i}$ are, respectively, the marginal effects of the sex and occupation variables subject to one normalization constraint. For identification, we conveniently code SEX as a dummy variable: SEX = 1 if female; $\operatorname{SEX}=0$ otherwise. That is, we normalize $\gamma_{1}=0$ and define $\gamma_{2}=\delta$ as the coefficient of SEX. After this normalization, there is 1 $\delta$ parameter and $J \alpha$ parameters. Giving a unique $\alpha_{j}$ for each occupation, we impose no constraint on the marginal parameters $\alpha_{j} s$. This is consistent with our objective not to model occupational choice per se but to model male-female differences in occupational choice. For various reasons, some occupations are more popular among youth than others; a more theoretically interesting question is whether occupational choice is sex-typed after popularity differences across occupations are controlled for. Under the independence model, the logit of being female among those choosing an occupation is

$$
\operatorname{logit} t_{j}=\log \left(F_{2 j} / F_{1 j}\right)=\delta \text {. }
$$

\section{REFLECTION MODEL}

We derive the reflection model from cognitive development theory (Kohlberg 1966) and social learning theory (Walker 1981; Bandura 1986) in psychological literature on sex roles. Cognitive development theory and social learning theory identify the whole social environment at the societal level as the ultimate source of sex-typing and thus differ from many studies that focus on the influences of such single actors as parents, teachers, older siblings, and peers (e.g., Seater and 
Ridgeway 1976; Macke and Morgan 1978; Stake and Granger 1978; Smith and Erb 1986). According to these theories, specific actors are viewed only as socializing agents of the larger environment, and sex-role information is conveyed to children through multiple sources (such as schools, TV programs, and toys) that cannot and should not be specified. As Perry and Bussey (1979) argued, children need to form abstractions of sex-appropriate behaviors from their concrete observations before they can imitate, and this cognitive process involves too many individuals for any single actor to play a dominant role.

Our reflection model hypothesizes that sex differences in youth's occupational choices reflect the actual distribution of men and women in the adult labor force. Operationally, we are interested in testing whether a high representation of female workers has a positive effect on young women's choice of the occupation, and vice versa. We base this model on the assumption that sex-typing of occupational choice is the direct result of the salience (or "frequency") of sex-linked role models (Perry and Bussey 1979). ${ }^{2}$ In all forms of information transmitted in socialization, female and male workers are typically cast in work roles that are consistent with occupational sex segregation of the larger society. The more female incumbents there are in an occupation, the more consistently it becomes identified as a female occupation in all forms of media, and the more likely it is that the occupation will be perceived as female-appropriate by youth, and vice versa. As a result, young women develop a taste for female-typical occupations, and young men come to prefer male-typical occupations.

To empirically implement the reflection model, we devise a measure of representation for each sex, as the logarithm of the number of workers by each sex in an occupational category. ${ }^{3}$ Let $N_{1 j}$ and $N_{2 j}$ denote, respectively, the numbers of male and female workers in the $j$ th occupation. Separately for males and females, the reflection model can be written in the log-linear form as follows. For males,

$$
\log \left(F_{1 j}\right)=\alpha_{j}+\beta_{1} \log \left(N_{1 j}\right)
$$

for females,

$$
\log \left(F_{2 j}\right)=\delta+\alpha_{j}+\beta_{1} \log \left(N_{2 j}\right)
$$


From Equations $3 a$ and $3 b$, we can easily derive the following expression for the logit of being female among those choosing an occupation:

$$
\operatorname{logit}{ }_{j}=\log \left(F_{2 j} / F_{1 j}\right)=\delta+\beta_{1} \log \left(N_{2 j} / N_{1 j}\right)=\delta+\beta_{1} \text { LLFF }_{j},
$$

where LFLF, an acronym of "the logit of being female in the labor force," measures the participation of female workers, relative to that of male workers, in an occupation:

\section{$\mathrm{LFLF}_{j}=\log [\mathrm{P}($ female $\mid$ Occ. $=j) / \mathrm{P}($ male $\mid$ Occ. $=j)]$}

Equation 4 highlights the term reflection model, for if $\beta_{1}$ is unity, the amount of sex segregation in occupational choice exactly reflects the amount of sex segregation in the labor force. Note that the independence model is a special case of the reflection model.

\section{EXPECTATION MODEL}

The human capital perspective of occupational choice assumes that individuals rationally choose occupations that offer them the greatest monetary (and, to some, nonmonetary) returns. See, for example, Boskin's (1974:390) emphasis on expected returns in earnings. According to this neoclassical economic view, occupational sex segregation can be explained in terms of women's needs for intermittent employment to care for children (Zellner 1975; Polachek 1979, 1981). Female-dominated occupations are said not to require continuous human capital investments but to offer attractive starting wages and flexible work schedules; in contrast, male-dominated occupations are characterized as having steady and sharp appreciation of human capital with experience. Thus, occupational sex segregation is explained by women's tastes for traditionally female occupations because these occupations are believed to be more compatible with their career needs.

Our expectation model builds on the reflection model by incorporating youth's projected future earnings. We assume that youth predict their future earnings based on the experiences of adult workers of their own sex and choose occupations that would maximize their expected earnings. As will be shown later, after we control for the unique attractiveness of different occupations, the above statement is tanta- 
mount to the prediction that occupations with relatively smaller average gaps in earnings between female and male workers will be more attractive to young women than those with relatively larger gaps. This theoretical model capitalizes on the interoccupational variation in pay equity between the sexes, in a parallel fashion to the argument that occupations differ in the extent to which education functions as a universalistic factor (Yamaguchi 1983; Hout 1988).

The rationale of this model is further supported by Becker's (1971) pioneering work on discrimination. Becker (1971:90-97) argued that "discrimination is the prime determinant of the relative occupational distribution of Negroes (and Jews)" (p. 96), because Blacks and persons of Jewish background rationally choose occupations to avoid discrimination. We borrow this reasoning and suggest that young women's likelihood of choosing an occupation is positively related to the perceived equity between female and male workers in the occupation, due to young women's desire to avoid sex discrimination. Operationally, the expectation model tests, in addition to the reflection effect, whether the ratio of the average hourly wage of female workers to that of male workers in an occupation has a positive effect on women's choice of that occupation. The word expectation is intended to convey the notion that occupational choice is determined by the individuals' rational calculation of "the expected benefits and costs" associated with the chosen occupation (Feather and Said 1983:123).

Thus, the expectation model adds to the reflection model an additional parameter measuring the effect of the average wage. Let $W_{A G E}$ and $W_{1 j} E_{2 j}$ denote, respectively, the wage rates of male and female workers in the $j$ th occupation. For males,

$$
\log \left(F_{1 j}\right)=\alpha_{j}+\beta_{1} \log \left(N_{1 j}\right)+\beta_{2} \log \left(\text { WAGE }_{1 j}\right)
$$

for females,

$$
\log \left(F_{2 j}\right)=\delta+\alpha_{j}+\beta_{1} \log \left(N_{2 j}\right)+\beta_{2} \log \left(\mathrm{WAGE}_{2 j}\right) .
$$

Taking the difference between Equation $5 \mathrm{~b}$ and Equation $5 \mathrm{a}$ yields

$$
\begin{gathered}
\operatorname{logit} t_{j}=\delta+\beta_{1} \log \left(N_{2 j} / N_{1 j}\right)+\beta_{2} \log \left(\mathrm{WAGE}_{2 j} / \mathrm{WAGE}_{1 j}\right)= \\
\delta+\beta_{1} \mathrm{LFLF}_{j}+\beta_{2} \mathrm{EQUITY}_{j}
\end{gathered}
$$


where EQUITY is measured by the logarithm of the wage ratio between female workers and male workers. In other words, the model predicts that the more equitable an occupation is in terms of female workers' wages being closer to those of male workers, the more likely a young woman is to want to enter the occupation. This equity effect is net of the reflection effect captured by LFLF and the unique occupation effect $\alpha_{j}$.

\section{REFERENCE MODEL}

The classic study on American soldiers during World War II by Stouffer and his associates (1949) found that soldiers' attitudes toward induction and appraisals of chances for promotion resulted more from their perceptions of themselves relative to others similar to them than from their actual experiences. This important finding led Stouffer and his associates to resort to the concept of relative deprivation as a social psychological explanation. Based on their published results, Merton (1968, chaps. 10 and 11) further synthesized and formalized reference group theory, which places the individual in relation to groups to which he or she belongs or aspires to belong. The most distinctive feature of Merton's reference group theory is that reference groups provide the individual with "a frame of comparison relative to which the individual evaluates himself and others" (p. 337, emphasis added).

Applying reference group theory to our study, we propose the reference model. This model hypothesizes that a young person learns the likelihood of his or her relative economic position from the experiences of men and women in the labor force and that this information affects the person's occupational preferences. The reference model essentially competes with and expands the expectation model, for it places special importance on relative positions rather than just the average in the sex-specific distributions of economic returns (i.e., wage rates). Specifically, we disaggregate workers in an occupation into three groups along the wage distribution: highly successful workers (top earners), unsuccessful workers (low earners), and other workers. For each sex, we expect that youth's likelihood of choosing an occupation is positively related to the proportion of highly successful workers (top earners) and negatively related to the proportion of 
unsuccessful workers (low earners) in the occupation. Operationally, we use the proportion of workers whose wage rates exceeded the 90th percentile within an occupation as a measure for the top-earner rate and the proportion of workers in an occupation who did not work as a measure of the low-earner rate. We expect that such a breakdown of the earnings distribution will provide a better explanation than that offered by the gross average difference in earnings between the two sexes.

The key difference between the expectation model and the reference model is that the latter capitalizes on the distribution of wages instead of the mean of wages. According to the reference model, it is not the expected wage but the likelihood of being highly successful or unsuccessful that matters most. We assume that being a top earner or low earner in an occupation has certain attractions no matter which occupation a person is in. For incumbents in the middle of the distribution, we assign the utility to be proportional to the logarithm of their average wages, as in the expectation model. Let $\mathrm{P}(T), \mathrm{P}(L)$, and $\mathrm{P}(M)$ denote, respectively, the probabilities that an incumbent is highly successful (top earner), unsuccessful (low earner), and in the middle. The expected preference value function $(V)$ is then

$$
\mathrm{E}(V)=\mathrm{P}(T) \mathrm{E}(V \mid T)+\mathrm{P}(L) \mathrm{E}(V \mid L)+\mathrm{P}(M) \mathrm{E}(V \mid M) .
$$

Incorporating Equation 7 into a statistical model with measured variables, the reference model is, for males,

$$
\begin{gathered}
\log \left(F_{1 j}\right)=\alpha_{j}+\beta_{1} \log \left(N_{1 j}\right)+\beta_{3} \mathrm{P}\left(T_{1 j}\right)+ \\
\beta_{4} \mathrm{P}\left(L_{1 j}\right)+\beta_{5}\left[1-\mathrm{P}\left(T_{1 j}\right)-\mathrm{P}\left(L_{1 j}\right)\right] \log \left(\text { WAGEM }_{1 j}\right) ;
\end{gathered}
$$

and for females,

$$
\begin{gathered}
\log \left(F_{2 j}\right)=\delta+\alpha_{j}+\beta_{1} \log \left(N_{2 j}\right)+\beta_{3} \mathrm{P}\left(T_{2 j}\right)+ \\
\beta_{4} \mathrm{P}\left(L_{2 j}\right)+\beta_{5}\left[1-\mathrm{P}\left(T_{2 j}\right)-\mathrm{P}\left(L_{2 j}\right)\right] \log \left(\mathrm{WAGEM}_{2 j}\right),
\end{gathered}
$$

where WAGEM is the average wage rate for those in the middle. Here, $\beta_{3}$ and $\beta_{4}$ measure (empirically) the relative importance placed on belonging to the top- and low-earnings groups. It follows from Equations $8 \mathrm{a}$ and $8 \mathrm{~b}$ that 


$$
\begin{gathered}
\operatorname{logit} t_{j}=\delta+\beta_{1} \log \left(N_{2 j} / N_{1 j}\right)+\beta_{3}\left[\mathrm{P}\left(T_{2 j}\right)-\mathrm{P}\left(T_{1 j}\right)\right]+\beta_{4}\left[\mathrm{P}\left(L_{2 j}\right)-\mathrm{P}\left(L_{1 j}\right)\right] \\
+\beta_{5}\left\{\left[1-\mathrm{P}\left(T_{2 j}\right)-\mathrm{P}\left(L_{2 j}\right)\right] \log \left(\mathrm{WAGEM}_{2 j}\right)-\left[1-\mathrm{P}\left(T_{1 j}\right)-\mathrm{P}\left(L_{1 j}\right)\right] \log \left(\mathrm{WAGEM}_{1 j}\right)\right\} \\
=\delta+\beta_{1} \mathrm{LFLF}_{j}+\beta_{3} \Delta \mathrm{TOP}_{j}+\beta_{4} \Delta \mathrm{LOW}_{j}+\beta_{5} \mathrm{EQUITYM}_{j},
\end{gathered}
$$

where $\triangle T O P$ and $\triangle \mathrm{LOW}$ are female-male differences in the probabilities of being a top or low wage earner and EQUITYM is the logarithm of the power-weighted wage ratio between female workers and male workers who are not in the upper and lower ends of the wage distribution, with weights being the probabilities that workers are in the middle. In this way, the overall impact of wages is broken down into three components in the reference model: the emulation effect due to $\triangle T O P$, the avoidance effect due to $\triangle \mathrm{LOW}$, and the residual expectation effect due to EQUITYM.

\section{THE DATA}

This research involves analysis of data from four sources. The National Longitudinal Study of the Class of 1972 (NLS-72) is used for the analysis of career aspirations of high school seniors in 1972. ${ }^{4}$ Based on three-digit census occupational codes, the detailed occupations are grouped into 47 categories according to the rule of maintaining the within-group homogeneity and preserving the information pertaining to sex segregation of occupational choice. The resulting cross-tabulation of sex by occupational choice from the NLS-72 data is presented in columns 2 and 3 of Table 1.

Gender-specific characteristics of experienced workers between ages 21 and 64 in the 47 occupations are obtained from the 1\% Public Use Sample of the 1970 census. In addition to sex composition for each occupation, we calculate four measures of hourly earnings for each sex and occupation combination: (1) the average hourly wage, ${ }^{5}$ (2) the proportion of top earners, (3) the proportion of low earners, and (4) the average hourly wage for workers who are neither top earners nor low earners. These four measures form the bases for our predictors LFLF, EQUITY, $\triangle \mathrm{TOP}, \triangle \mathrm{LOW}$, and EQUITYM in loglinear models discussed in the last section. That is, we treat the measured variables in terms of averages and proportions from the 
TABLE 1: Linking NLS-72 Data and 1970 Census Data Through 47 Major Occupations

\begin{tabular}{|c|c|c|c|c|c|}
\hline \multirow[b]{2}{*}{ Occupation } & \multicolumn{2}{|c|}{ NLS-72 Data } & \multicolumn{3}{|c|}{$\begin{array}{c}1970 \text { Census } \\
\text { (1\% Public Use Sample) }\end{array}$} \\
\hline & \%Female & (n) & \%Female & Wage Ratio & (n) \\
\hline Life scientists & $32.52 \%$ & $(163)$ & $22.27 \%$ & $83.09 \%$ & $(687)$ \\
\hline Physical scientists & 21.95 & $(82)$ & 9.99 & 70.89 & $(1,961)$ \\
\hline Social scientists & 62.13 & $(235)$ & 19.40 & 80.16 & $(1,490)$ \\
\hline Mathematicians & 53.85 & (26) & 25.45 & 64.56 & $(550)$ \\
\hline Engineers & 1.94 & $(465)$ & 1.54 & 90.07 & $(12,361)$ \\
\hline Architects & 5.00 & $(140)$ & 3.85 & 53.28 & $(546)$ \\
\hline Physicians and dentists & 34.13 & (630) & 8.57 & 70.83 & $(4,876)$ \\
\hline Nurses, dietitians, and therapists & 95.82 & $(886)$ & 94.80 & 85.45 & $(9,102)$ \\
\hline Elementary and preschool teachers & 94.31 & $(369)$ & 86.79 & 86.03 & $(17,341)$ \\
\hline $\begin{array}{l}\text { Secondary and vocational } \\
\text { education teachers }\end{array}$ & 66.10 & $(1,112)$ & 46.02 & 89.88 & $(15,298)$ \\
\hline Science, engineering technicians & 9.83 & $(234)$ & 10.74 & 73.89 & $(7,662)$ \\
\hline Health technologists and technicians & 81.11 & $(270)$ & 64.44 & 68.76 & $(2,916)$ \\
\hline Other technologists and technicians & 11.76 & (119) & 16.53 & 54.57 & $(2,650)$ \\
\hline Computer specialists & 37.93 & (174) & 18.01 & 81.71 & $(3,293)$ \\
\hline Writers, artists, and entertainers & 47.52 & $(947)$ & 30.32 & 82.52 & $(8,863)$ \\
\hline Lawyers and judges & 23.45 & (290) & 4.94 & 65.27 & $(2,532)$ \\
\hline Librarians, archivists, and curators & 91.30 & (23) & 79.93 & 81.26 & $(1,101)$ \\
\hline Social and recreation workers & 77.49 & $(382)$ & 60.75 & 91.97 & $(2,525)$ \\
\hline Religious workers & 39.42 & (104) & 9.61 & 86.08 & $(2,332)$ \\
\hline Accountants & 35.73 & (347) & 25.14 & 65.26 & $(6,590)$ \\
\hline Managers and administrators, public & 12.50 & $(40)$ & 21.95 & 69.68 & $(4,669)$ \\
\hline Managers and administrators & 28.14 & $(526)$ & 16.48 & 59.58 & $(54,340)$ \\
\hline Sales workers, retail & 61.54 & (208) & 56.00 & 63.48 & $(21,184)$ \\
\hline Sales workers & 44.23 & $(52)$ & 18.96 & 71.69 & $(21,609)$ \\
\hline Office machine operators & 90.70 & (129) & 81.02 & 72.70 & $(8,229)$ \\
\hline Bookkeepers & 78.82 & $(85)$ & 82.75 & 72.13 & $(14,922)$ \\
\hline Secretaries & 99.62 & $(1,316)$ & 96.80 & 60.55 & $(32,498)$ \\
\hline Clerical workers, general & 92.40 & $(487)$ & 56.44 & 69.12 & $(55,647)$ \\
\hline Automobile mechanics and repairmen & 0.34 & $(295)$ & 1.25 & 76.73 & $(8,288)$ \\
\hline General mechanics and repairmen & 0.32 & (314) & 2.58 & 74.09 & $(17,365)$ \\
\hline Carpenters & 0.95 & $(105)$ & 1.50 & 69.15 & $(8,917)$ \\
\hline Electricians & 0.00 & (107) & 1.64 & 72.01 & $(5,734)$ \\
\hline Other construction trades & 19.42 & (206) & 3.98 & 75.81 & $(18,836)$ \\
\hline Metal craftsmen, except mechanics & 1.43 & $(70)$ & 3.24 & 72.06 & $(10,526)$ \\
\hline Other craftsmen & 15.73 & (89) & 10.98 & 64.15 & $(26,694)$ \\
\hline Textile operators & 88.00 & (75) & 80.63 & 77.10 & $(16,466)$ \\
\hline Metalworking operators & 0.00 & (85) & 16.19 & 67.41 & $(9,801)$ \\
\hline Transport equipment operators & 4.55 & (66) & 4.39 & 91.12 & $(26,540)$ \\
\hline $\begin{array}{l}\text { Operators, except textile, metalworking } \\
\text { and transportation }\end{array}$ & 29.82 & $(218)$ & 35.09 & 68.85 & $(62,149)$ \\
\hline Laborers, except farm & 13.45 & (238) & 8.85 & 73.39 & $(26,643)$ \\
\hline
\end{tabular}


TABLE 1: Continued

\begin{tabular}{|c|c|c|c|c|c|}
\hline \multirow[b]{2}{*}{ Occupation } & \multicolumn{2}{|c|}{ NLS-72 Data } & \multicolumn{3}{|c|}{$\begin{array}{c}1970 \text { Census } \\
\text { (1\% Public Use Sample) }\end{array}$} \\
\hline & \%Female & (n) & \%Female & Wage Ratio & (n) \\
\hline Farmers and farm laborers & 7.77 & (206) & 10.46 & 81.31 & $(17,994)$ \\
\hline Forestry and fishing occupations & 5.95 & (168) & 3.51 & 69.95 & (684) \\
\hline Cleaning and food service workers & 56.41 & $(78)$ & 65.03 & 69.47 & $(44,226)$ \\
\hline Health service workers & 94.38 & (249) & 88.81 & 82.82 & $(10,197)$ \\
\hline Personal service workers & 98.35 & (182) & 56.52 & 104.85 & $(2,102)$ \\
\hline $\begin{array}{l}\text { Barbers, hairdressers, and } \\
\text { cosmetologists }\end{array}$ & 95.31 & (256) & 68.23 & 87.35 & $(5,786)$ \\
\hline Protective service workers & 8.58 & (233) & 6.30 & 82.61 & $(8,867)$ \\
\hline
\end{tabular}

NOTE: NLS-72 = National Longitudinal Study of the Class of 1972. Wage ratio is the ratio of the average hourly wage of female workers to that of male workers.

1970 1\% Public Use Sample as if they were population means and probabilities.

Results from the analysis of NLS-72 are corroborated with data from the 1979 National Longitudinal Survey of Labor Force Behavior-Youth Cohort (NLSY-79). Although NLSY-79 is not an ideal replicate of NLS-72, NLSY-79 collected youth occupational choice in a manner similar to NLS-72. We select NLSY-79 respondents in 9th to 12th grades in 1979 to ensure enough observations while retaining a certain degree of comparability. The labor force composition in 1979 is approximated by 1977-1979 March Current Population Surveys (CPS).

RESULTS FROM NLS-72 AND 1970 CENSUS

\section{DESCRIPTIVE RESULTS}

To understand the general characteristics of the students' aspirations, we first compare the descriptive statistics for the NLS-72 respondents and for the civilian labor force presented in Table 1. Students tended to overestimate their future occupational status. For example, many more students reported their desire to enter professional occupations than would be able to in reality. We find that 58 
percent of the NLS-72 respondents aspire to professional occupations (from life scientists to managers and administrators). However, workers in these occupations constituted only 25 percent of the actual U.S. labor force in 1970 .

Table 1 clearly portrays the tendency for young women and men to aspire to distinct, limited, and sex-specific ranges of occupations prior to entering the labor force. For instance, more than 90 percent of students planning to become nurses or elementary school teachers are women; whereas over 90 percent of those planning to become engineers or architects are men. Occupational sex segregation in the workforce is maintained in the respondents' desired occupations. For the occupational classification scheme in Table 1 , the index of dissimilarity for the total civilian labor force is 58.26 , whereas the index for the NLS-72 respondents in their occupational aspirations is 64.21 . $^{6}$ Furthermore, the close link between sex segregation of career aspirations and sex segregation of occupations is apparent in Table 1.

Net of the absolute share of female workers in an occupation, the economic standing of female workers relative to that of male workers may have additional influences. The ratio of women's average hourly earnings to men's (Table 1, column 5) measures the variation in gender equity across occupations. It varies from barely over half for some occupations (e.g., architects, other technologists and technicians) to near unity for other occupations (e.g., engineers, social and recreation workers, transport equipment operators, and personal service workers).

\section{LOG-LINEAR MODELS RESULTS}

With the assumption that the cell frequency $\left(f_{i j}\right)$ results from a multinomial distribution, log-linear regressions of Equations 1, 3, 5, and 8 can be estimated via maximum likelihood (ML) assuming a Poisson distribution. We use three measures to assess the goodness of fit of a model: (1) the log-likelihood ratio chi-square statistic $\left(L^{2}\right),(2)$ the Pearson chi-square statistic $\left(X^{2}\right)$, and (3) the BIC statistic. Asymptotically, both $L^{2}$ and $X^{2}$ follow a chi-square distribution, if the model is true, with the same degrees of freedom equal to the number of cells minus the number of parameters estimated. Moreover, the difference in $L^{2}$ between two nested models is also distributed as chi-square under the assumption that the simpler model is true. BIC is a statistic 
proposed by Schwarz (1978) and adapted by Raftery (1986) for contingency table settings: $B I C=L^{2}-(D F) \log (n)$, where $L^{2}$ is the $\log$-likelihood ratio statistic, $D F$ is the associated degrees of freedom, and $n$ is the sample size. When assessing the fits of two or more competing models, the model with the smallest value of $B I C$ statistic is selected as the best fitting.

In Table 2, we present the goodness-of-fit statistics for four loglinear models. We start with the baseline independence model (Model 0 ). The independence model imposes on the data the naive assumption that sex is unrelated to occupational choice, while leaving the marginal distributions of sex and occupational choice to be free. The model fits the data poorly $\left(L^{2}=8204.0\right.$ and $X^{2}=6570.5$, each with 46 degrees of freedom; and $B I C=7768.0$ ) and is, therefore, rejected outright.

Adding the representation of each sex in the labor force computed from the 1970 census as an explanatory variable, the reflection model (Model 1) is a great improvement over Model 0: $L^{2}$ decreases by 90 percent to 853.8 for 1 degree of freedom; BIC decreases by 95 percent to 427.2. Clearly, the reflection hypothesis can account for most of the observed association between sex and occupational choice. In other words, we find that the occupational choices of students seem to be modeled after the sex-typed occupational structure-that is, the aggregate experiences of adult workers in the labor force.

In the expectation model (Model 2), we try to further explain the association between sex and occupational choice by including the sex-specific average hourly wages as specified in Equation 5. By the $L^{2}$ and $X^{2}$ statistics, Model 2 is an improvement over Model 1: $L^{2}$ is reduced by 18.4 to 835.4 for 1 degree of freedom, and $B I C$ by 8.9 to 418.3.

In the reference model (Model 3), we replace the average hourly wages by three distributional measures of sex differences in hourly wages as explanatory variables. Model 2 is not nested within Model 3, but Model 1 is nested within both Models 2 and 3. By the $L^{2}$ and BIC statistics, Model 3 is much better than Model $1\left(L^{2}\right.$ is reduced by 72.5 for 3 degrees of freedom; BIC drops from 427.2 to 383.1). Between Models 2 and 3, Model 3 is preferred according to the $B I C$ criterion. In other words, the three distributional measures of wages account for more association between sex and occupational choice than does the single measure of average difference in wages. 
TABLE 2: Goodness-of-Fit Statistics for Log-Linear Models Applied to NLS-72 Data

\begin{tabular}{llrrrr}
\hline Model Description & \multicolumn{2}{c}{$L^{2}$} & \multicolumn{1}{c}{$X^{2}$} & DF & BIC \\
\hline 0 & Independence model & 8204.0 & 6570.5 & 46 & 7768.0 \\
1 & Reflection model & 853.8 & 799.4 & 45 & 427.2 \\
2 & Expectation model & 835.4 & 779.3 & 44 & 418.3 \\
3 & Reference model & 781.3 & 737.4 & 42 & 383.1 \\
\hline
\end{tabular}

NOTE: NLS-72 = National Longitudinal Study of the Class of 1972. $L^{2}$ is the log-likelihood ratio chi-square statistic, and $X^{2}$ is the Pearson chi-square statistic, both with the degrees of freedom reported in column $D F . B I C=L^{2}-(D F) \log (n)$, where $n$ is the sample size $(13,081)$. See text for explanation of the models.

In Table 3, we present the estimated parameters for the effects of the occupational gender inequality on students' occupational choices from each of the models. A significant finding is that the LFLF parameter (the reflection effect) is estimated to be close to unity for all the models. That this parameter is close to unity has a substantive meaning: It shows that the amount of sex segregation in the labor force is almost perfectly reproduced in youth's occupational choices. The consistency of the estimated reflection effect parameter across the expectation and reference models indicates that the influence of occupational sex segregation on sex-typing of occupational preferences of high school students is robust to the inclusion of other economic characteristics of the occupational structure.

The expectation effect represented by the coefficient of EQUITY is in the expected positive direction. The higher female workers' average wages are relative to male workers', the greater the likelihood that the occupation is chosen by women. For a hypothetical change in EQUITY from 50 percent to 100 percent, for example, the logit of being female in occupational choice significantly increases by 0.512 , under the assumption that the sex composition of the occupation remains the same (i.e., no change due to the reflection effect). This means that, given the same level of women's representation, an occupation of greater economic disparity between men and women is less attractive than an otherwise comparable occupation of less economic disparity. This finding is consistent with Becker's (1971) theory of discrimination and its implication for occupational choice (pp. 90-93). 
TABLE 3: Selected Logit Parameters for Log-Linear Models Reported in Table 2

\begin{tabular}{llcc}
\hline & \multicolumn{3}{c}{ Log-Linear Models } \\
\cline { 2 - 4 } Logit Parameter & 1. Reflection & 2. Expectation & 3. Reference \\
\hline SEX (marginal effect) & $0.865(0.029)$ & $1.049(0.052)$ & $1.437(0.076)$ \\
LFLF (reflection effect) & $1.020(0.018)$ & $1.002(0.018)$ & $1.017(0.025)$ \\
EQUITY (expectation effect) & & $0.738(0.172)$ & \\
$\Delta$ TOP (emulation effect) & & & $2.072(0.597)$ \\
$\Delta$ LOW (avoidance effect) & & $-9.093(1.325)$ \\
EQUITYM (residual & & \\
expectation effect) & & & $0.376(0.346)$ \\
\hline
\end{tabular}

NOTE: Estimated standard errors are in parentheses.

The coefficients of the three distributional measures of wage differences ( $\triangle T O P$, $\triangle \mathrm{LOW}$, and EQUITYM) are labeled, respectively, as the emulation effect, the avoidance effect, and the residual expectation effect. As expected, the emulation effect is estimated to be positive, and the avoidance effect is estimated to be negative; both are statistically significant from zero. Although the estimate of the residual expectation effect is in the hypothesized positive direction, it is not statistically significant from zero. This shows that most of the expectation effect in terms of average differences in wages between men and women is captured by distributional differences in wages between the sexes-more exactly, proportions attaining the top 10 percentile and falling into zero earners. The estimated magnitude of the emulation effect indicates that an increase of 10 percent in women's propensity to belong in the top 10 percentile relative to men's would result in an increase of 0.207 in the logit of being female among those choosing the occupation. Likewise, an increase of 10 percent in women's propensity to be zero earners relative to men's would result in a decrease of 0.909 in the logit of being female among those choosing the occupation.

\section{CHANGES FROM 1972 TO 1979}

As Rytina and Bianchi (1984) observed, a number of occupations became significantly less sex segregated over the 1970-1980 decade. 
According to our argument that gender inequality in the occupational structure has socializing effects on the occupational choices of young men and women, the changes in the occupational structure should influence changes in occupational choices. We expect occupational preferences of youth to respond to the changes in occupational structure. In other words, sex-typing of occupational choice in a later period can be better explained by predictors for the contemporaneous occupational structure than by predictors for an earlier period, assuming that the same or similar log-linear models apply to both periods.

In this section, we corroborate the earlier log-linear model results with data from the NLSY-79 survey. We approximate the composition of the occupational structure in 1979 with data from the 1977-1979 March CPS. Table 4 gives the percentage female by occupational choice and two key characteristics of the adult labor force computed from the 1977-1979 CPS. The association between sex and occupational choice in the NLSY-79 data is presented in the second column of Table 4. Comparing Table 4 to Table 1, we observe that for some occupations at least, the percentage of women interested in choosing an occupation changed during the 1972-1979 period in tandem with the percentage of women in the labor force. For example, for all scientific and engineering occupations, except for mathematicians due to a small sample size of 3 in NLSY-79, women's actual representation in these occupations (column 4) as well as women's expressed interest in them (column 2) increased.

To examine this more formally, we fit log-linear models based on predictors computed from the 1970 census and then fit parallel models based on predictors computed from the 1977-1979 CPS. If sex-typing of occupational choice indeed reflects socialized tastes that are influenced by the current composition of adult workers in the labor force, we would expect the models based on predictors computed from the 1977-1979 CPS to perform better than the models based on predictors computed from the 1970 census. Although the combined file of the 1977-1979 March CPS is large as a whole $(N=170,311)$, its breakdown into the 47 occupational categories leaves several occupations with too few observations (say, less than 500) to reliably calculate several occupational characteristics. We found that the wage ratio variable between female and male workers is reasonably reliable for 
TABLE 4: Linking NLSY-79 Data and 1977-1979 March CPS Data Through 47 Major Occupations

\begin{tabular}{|c|c|c|c|c|c|}
\hline \multirow[b]{2}{*}{ Occupation } & \multicolumn{2}{|c|}{ NLSY-79 Data } & \multicolumn{3}{|c|}{ 1977-1979 March CPS Data } \\
\hline & $\%$ Female & (n) & $\%$ Female & Wage Ratio & (n) \\
\hline Life scientists & $38.89 \%$ & (36) & $23.77 \%$ & $89.03 \%$ & (244) \\
\hline Physical scientists & 24.00 & (25) & 13.45 & 110.55 & (476) \\
\hline Social scientists & 80.00 & (55) & 31.09 & 89.58 & (669) \\
\hline Mathematicians & 33.33 & (3) & 24.52 & 46.39 & (155) \\
\hline Engineers & 7.33 & $(150)$ & 2.47 & 79.03 & $(2,671)$ \\
\hline Architects & 17.86 & $(84)$ & 2.41 & 76.32 & (166) \\
\hline Physicians and dentists & 53.28 & (244) & 10.91 & 75.68 & $(1,356)$ \\
\hline Nurses, dietitians, and therapists & 96.81 & (188) & 92.52 & 97.91 & $(2,728)$ \\
\hline Elementary and preschool teachers & 85.61 & (139) & 89.07 & 70.54 & $(4,931)$ \\
\hline \multicolumn{6}{|l|}{ Secondary and vocational } \\
\hline education teachers & 64.37 & $(87)$ & 49.75 & 95.29 & $(4,336)$ \\
\hline Science, engineering technicians & 21.15 & $(52)$ & 15.07 & 76.22 & $(1,924)$ \\
\hline Health technologists and technicians & 72.73 & (55) & 66.23 & 78.01 & $(1,137)$ \\
\hline Other technologists and technicians & 8.00 & (75) & 28.02 & 52.05 & $(653)$ \\
\hline Computer specialists & 45.95 & (74) & 22.05 & 70.28 & $(1,066)$ \\
\hline Writers, artists, and entertainers & 43.64 & $(472)$ & 36.24 & 80.59 & $(2,903)$ \\
\hline Lawyers and judges & 43.08 & (130) & 10.75 & 54.32 & (930) \\
\hline Librarians, archivists, and curators & 0.00 & (1) & 81.00 & 78.34 & (421) \\
\hline Social and recreation workers & 76.60 & (47) & 60.04 & 83.39 & (901) \\
\hline Religious workers & 27.27 & (11) & 15.72 & 135.09 & (668) \\
\hline Accountants & 60.94 & (128) & 31.93 & 66.89 & $(1,876)$ \\
\hline Managers and administrators, public & 10.53 & (19) & 28.14 & 64.87 & $(1,752)$ \\
\hline Managers and administrators & 29.34 & $(317)$ & 23.13 & 59.92 & $(18,560)$ \\
\hline Sales workers, retail & 60.61 & (33) & 60.99 & 67.95 & $(4,235)$ \\
\hline Sales workers & 26.32 & (19) & 28.54 & 70.91 & $(5,746)$ \\
\hline Office machine operators & 60.98 & (41) & 81.26 & 75.23 & $(1,980)$ \\
\hline Bookkeepers & 82.35 & (17) & 91.25 & 71.33 & $(3,920)$ \\
\hline Secretaries & 98.89 & $(271)$ & 98.53 & 61.98 & $(8,569)$ \\
\hline Clerical workers, general & 74.47 & $(94)$ & 67.51 & 66.72 & $(15,487)$ \\
\hline Automobile mechanics and repairmen & 0.68 & $(148)$ & 0.61 & 62.79 & $(2,284)$ \\
\hline General mechanics and repairmen & 4.07 & $(123)$ & 2.24 & 82.63 & $(4,777)$ \\
\hline Carpenters & 0.99 & $(101)$ & 1.36 & 49.59 & $(2,433)$ \\
\hline Electricians & 2.74 & (73) & 0.63 & 48.77 & $(1,430)$ \\
\hline Other construction trades & 35.29 & (68) & 5.14 & 67.77 & $(4,491)$ \\
\hline Metal craftsmen, except mechanics & 0.00 & (25) & 3.36 & 65.71 & $(2,349)$ \\
\hline Other craftsmen & 26.92 & (26) & 13.46 & 57.64 & $(5,693)$ \\
\hline Textile operators & 100.00 & (6) & 83.85 & 77.31 & $(3,058)$ \\
\hline Metalworking operators & 0.00 & (41) & 14.74 & 65.36 & $(2,157)$ \\
\hline Transport equipment operators & 7.87 & $(127)$ & 7.11 & 65.57 & $(6,806)$ \\
\hline \multicolumn{6}{|l|}{ Operators, except textile, metalworking } \\
\hline and transportation & 28.26 & (46) & 37.92 & 67.23 & $(13,326)$ \\
\hline Laborers, except farm & 26.67 & (45) & 11.07 & 70.31 & $(6,505)$ \\
\hline Farmers and farm laborers & 7.14 & $(56)$ & 16.76 & 75.60 & $(4,888)$ \\
\hline
\end{tabular}


TABLE 4: Continued

\begin{tabular}{|c|c|c|c|c|c|}
\hline \multirow[b]{2}{*}{ Occupation } & \multicolumn{2}{|c|}{ NLSY-79 Data } & \multicolumn{3}{|c|}{ 1977-1979 March CPS Data } \\
\hline & $\%$ Female & (n) & $\%$ Female & Wage Ratio & (n) \\
\hline Forestry and fishing occupations & 12.16 & (74) & 5.98 & 86.47 & (251) \\
\hline Cleaning and food service workers & 60.71 & (28) & 64.60 & 70.17 & $(11,475)$ \\
\hline Health service workers & 93.18 & (44) & 90.29 & 63.52 & $(3,172)$ \\
\hline Personal service workers & 93.24 & (74) & 64.01 & 76.46 & (892) \\
\hline $\begin{array}{l}\text { Barbers, hairdressers, and } \\
\text { cosmetologists }\end{array}$ & 97.67 & (86) & 78.60 & 82.44 & $(1,290)$ \\
\hline Protective service workers & 23.81 & (84) & 9.17 & 91.91 & $(2,574)$ \\
\hline
\end{tabular}

NOTE: NLSY-79 = 1979 National Longitudinal Survey of Labor Force Behavior-Youth Cohort; CPS = Current Population Surveys. Wage ratio is the ratio of the average hourly wage of female workers to that of male workers.

all occupations but that the proportions belonging to the top and low ends of wage distributions are unreliable because they are based on a small number of cases for many occupations. Thus, we choose to limit our prediction exercise to the reflection model and the expectation model. We note that the reference model is actually a more refined version of the expectation model.

The prediction results are given in Table 5, which displays two panels of log-linear models applied to the cross-classification of sex by occupational choice from NLS-79. In the first panel, predictors from the 1970 census are used; in the second panel, predictors from the 1977-1979 CPS are used. In each panel, four models are fitted: the independence model, the reflection model, the expectation model, and the expectation model with fixed logit parameters estimated from the 1972 data. It is clear from the goodness-of-fit statistics that the independence model (Models A0 and B0) should be rejected outright $\left(L^{2}=2128.1\right.$ and $X^{2}=1747.2$ for 46 degrees of freedom, and $B I C=$ 1745.0). The reflection model fits the data much better. From Models A0 to A1, $L^{2}$ is reduced by 1652.0 to 476.1 for 1 degree of freedom, and $B I C$ is reduced by 1643.7 to 101.3. From Models B0 to B1, the comparable gains are even greater: $L^{2}$ is reduced by 1690.7 to 437.4 for 1 degree of freedom, and $B I C$ is reduced by 1682.4 to 62.6 . The expectation model does not improve the goodness of fit much in the first panel, in which predictors from the 1970 census are used, because from Models A1 to A2, $L^{2}$ is reduced only by 4.3 for 1 degree of 
TABLE 5: Goodness-of-Fit Statistics for Log-Linear Models Applied to NLSY-79 Data

\begin{tabular}{lrrrr}
\hline Model Description & \multicolumn{1}{c}{$L^{2}$} & $X^{2}$ & DF & BIC \\
\hline Predictors from 1970 census are used & & & \\
A0 Independence model & & & & \\
A1 Reflection model & 2128.1 & 1747.2 & 46 & 1745.0 \\
A2 Expectation model & 476.1 & 457.5 & 45 & 101.3 \\
A3 Expectation model, fixed logit & 471.8 & 456.5 & 44 & 105.3 \\
$\quad$ parameters & 556.4 & 666.3 & 46 & 173.3 \\
Predictors from 1977-1979 CPS are used & & & & \\
B0 Independence model & 2128.1 & 1747.2 & 46 & 1745.0 \\
B1 Reflection model & 437.4 & 417.4 & 45 & 62.6 \\
B2 Expectation model & 416.8 & 404.7 & 44 & 50.3 \\
B3 Expectation model, fixed logit & & & & \\
$\quad$ parameters & 492.1 & 568.7 & 46 & 109.0 \\
\hline
\end{tabular}

NOTE: NLSY-79 = 1979 National Longitudinal Survey of Labor Force Behavior-Youth Cohort; CPS = Current Population Surveys. Models A3 and B3 are the same as Models A2 and B2 except that the logit parameters of LFLF and EQUITY are fixed to be those estimated from the NLS-72 data-that is, Model 2 of Table 3.

a. In this panel, predictors (LFLF and EQUITY) computed from the 1970 census were used to predict the sex-typing of occupational choice observed in NLSY-79 (shown in Table 1).

b. In this panel, predictors (LFLF and EQUITY) computed from the 1977-1979 March CPS are used.

freedom, and $B I C$ rises to 105.3. In the second panel, the expectation model yields a greater improvement: $L^{2}$ is reduced by 20.6 for 1 degree of freedom, and $B I C$ drops to 50.3. The constrained Expectation Models A3 and B3 are interesting because the logit parameters (the reflection effect and the expectation effect) are fixed to those estimated from the NLS-72 data (reported in Table 3). Here again, predictors from the 1977-1979 CPS perform better than those from the 1970 census, as Model B3 fits the data better than Model A3 according to any of our goodness-of-fit criteria.

Table 6 gives the logit parameter estimates of the reflection model and the expectation model reported in Table 5. Let us compare the estimates against those for the 1972 data reported in Table 3. The difference in the marginal effect of sex is due to sampling design and nonresponse and will be ignored. The reflection effect was earlier estimated to be 1.002 with a standard error of 0.018 for the expectation model in 1972; for 1979, it is now estimated to be 0.757 with a standard error of 0.025 for Model A2 and 0.756 with a standard error of 0.026 for Model B2. We do not have a firm answer as to why the estimates 
TABLE 6: Selected Logit Parameters for Log-Linear Models Reported in Table 5

\begin{tabular}{lll}
\hline & \multicolumn{2}{c}{ Log-linear Models } \\
\cline { 2 - 3 } Logit Parameter & 1. Reflection & 2. Expectation \\
\hline Predictors from 1970 census are used & & \\
$\quad$ SEX (marginal effect) & $0.716(0.051)$ & $0.868(0.089)$ \\
LFLF (reflection effect) & $0.766(0.025)$ & $0.757(0.025)$ \\
EQUITY (expectation effect) & & $0.543(0.261)$ \\
Predictors from 1977-1979 CPS are used & $0.499(0.046)$ & $0.826(0.086)$ \\
SEX (marginal effect) & $0.775(0.026)$ & $0.756(0.026)$ \\
LFLF (reflection effect) & & $1.086(0.240)$ \\
EQUITY (expectation effect) & &
\end{tabular}

NOTE: CPS $=$ Current Population Surveys. Estimated standard errors are in parentheses.

differ so much, but we note a difference in survey instrument: NLS-72 asked respondents about their occupational plans, whereas NLSY-79 asked respondents about their occupational aspirations, and it is known that the latter are less sex-typed than the former (see Marini and Greenberger 1978).

The preceding analysis of trends is marred by other problems as well. First, the data being compared are from four samples and thus subject to sampling variability. Second, data from the two periods refer to two different populations: NLS-72 surveyed high school seniors, whereas our subsample of NLSY-79 included high school students in the 9 th to 12 th grades. Finally, the combined sample of the 1977-1979 March CPS has a different time lag with respect to the 1979 NLSY-79 as compared with the 1970 census with respect to the 1972 NLS-72. Both descriptions of the labor force are only approximations. Given these shortcomings, however, the prediction exercise yields unambiguous results showing the congruence between changes in the labor force structure and changes in youth's occupational choices.

\section{DISCUSSION AND CONCLUSION}

Why are women concentrated in low-paying occupations? To borrow Gambetta's (1987) analogy, "were they pushed, or did they jump?" The theoretical problem can be phrased in the following way. On one hand, most women are in female-dominated occupations; thus, 
it seems that structural forces are at work that pressure women to conform to traditional sex roles. On the other hand, however, at least some women choose male-dominated occupations, and it seems that an individual's preferences or intentional choice can make a difference. This raises the question of whether occupational sex segregation is really caused by individual preferences or by social structure.

Although recognizing the predominant importance of structural forces (see Jacobs 1989), we have not dismissed the rational choice perspective, which has proven powerful in explaining sex differences in occupational choice at the individual level (Boskin 1974; Zellner 1975; Polachek 1979, 1981). In our study, we reversed the question and asked why some traditionally male occupations are more appealing to young women than are others. Thus, in this study, we have combined the two perspectives of rational choice and social structure. We propose that rational choice is bounded by social structure on one hand and acts as an agent for social structure on the other.

To the youth making occupational choices, the current labor force can be viewed as the fundamental source (or indicator) of social structure. Our expectation model says that young individuals try to maximize their expected earnings, and our reference model says that they desire to outperform their peers and to avoid failures. There is a clear rationalistic basis to these two theoretical models. That neither model was rejected by our study is evidence that rational choice should not be discarded offhand. However, individuals' rational choices are highly bounded by social structure, in the sense that social structure dictates how rational choices are formed in the first place. In our study, for example, rational choices are based on the experiences of workers actually in the labor force.

Rational choice also functions as an agent for social structure. This is best seen in the strong reflection effect of occupational sex segregation in the labor force on the sex-typing of occupational choice. In our study, we focus on the occupational choices of two cohorts of high school students before their entry into the labor market. Their choices are rational in the sense that they are voluntary and are not subject to labor market forces that have plagued many earlier studies of occupational attainment (for a recent critique, see Coleman 1990:714). That 
is, we separate labor market effects from socialization and attempt to explain socialization outcomes by the structure of the labor market.

There are two possible reasons why women are more likely to choose female-typical jobs than male-typical jobs: (1) Their attempts to enter male-typical jobs are blocked by sex discrimination, overt or covert, in the labor market and (2) they do not aspire to male-typical jobs when making occupational choices. The results of this study are consistent with the second explanation, for we found the degree of sex segregation for planned occupations to be similar to that for actual occupations. In other words, the congruence of sex segregation between planned and actual occupations is indicative of the dominance of socialization prior to labor force participation in maintaining occupational sex segregation. Our results should not be interpreted as a rejection of the potential influence of labor market discrimination against women. Rather, we argue that, to a significant degree, sextyping of occupational choice occurs before high school students themselves enter the labor market. Young women may well plan their future occupations on the basis of their perceived career opportunities or anticipated sex discrimination in the labor market (Laws 1976; Herzog 1982; Eccles 1987).

Occupational plans are intentions, not realized outcomes. As Manski (1990) forcefully argued, information contained in such data is inherently limited, even if an individual's reported occupational plan is interpreted as the best probability statement of the individual's intention. This is so because the individual's intention changes frequently as conditions evolve, opportunities arise, and new information becomes available after the data are collected. Indeed, if we compare the NLS-72 respondents' realized occupations in 1979 to their planned occupations in 1972 within our 47-category classification, only 19.03 percent of the respondents realized their occupational plans by 1979 . Clearly, occupational plans have limited predictability at the individual level. However, the main objective of this study is not to predict future occupations of individuals but to test the theoretical argument that sex-linked role models explain the sex-typing of youth's occupational choice. It is precisely because such additional factors as labor market discrimination and family responsibilities have not yet directly exerted their influences on youth that youth's occupational plans are 
an ideal candidate for our study attempting to locate the sources and limits of socialization in sustaining occupational sex segregation.

We have hypothesized three theoretical models, each implying a different channel through which sex-linked occupational characteristics affect the sex-typing of occupational choice: (1) The reflection model specifies the reflection effect of the extent of occupational sex segregation in the labor force, (2) the expectation model specifies the expectation effect of the average pay equity between female and male workers, and (3) the reference model specifies the emulation and avoidance effects of sex differences in proportions of successful and unsuccessful workers. Although our data do not allow us to draw strictly causal inferences, our log-linear analyses yield empirical results in strong support of the reflection model and in weak support of the expectation model and the reference model. Judged from the goodness-of-fit statistics, however, our empirical models are far from fully explaining the sex-typing of occupational choice. Influences of occupational structure constitute only part of the explanation for the continuation of occupational sex segregation.

\section{NOTES}

1. For a recent study of occupational sex segregation using log-linear models, see Charles and Grusky (1995).

2. Even though this assumption has been confirmed in an experimental study (Heilman 1979), to the best of our knowledge, it has not been tested with nationally representative, observational data.

3. In fact, as will be shown later, it does not matter whether the number of workers of each sex or the proportion of workers of each sex is used.

4. Although we are aware of subtle differences, in this article, we treat occupational choice, occupational planning, and occupational aspiration synonymously (see also Marini and Greenberger 1978; Marini and Brinton 1984).

5. These earnings figures were checked against published figures (U.S. Bureau of the Census 1973) and found to be accurate. Earnings may be slightly underestimated because the upper limit on reported yearly income was $\$ 50,000$ for the 1970 census.

6. We note that the index of dissimilarity for the 1970 census data across the 47 major categories is only slightly smaller than that based on the detailed three-digit classification, which is 65.90 (Beller 1984), largely due to our effort to combine detailed occupations into groups that maintain the salience of occupational sex segregation. 


\section{REFERENCES}

Bandura, Albert. 1986. Social Foundations of Thought and Action. Englewood Cliffs, NJ: Prentice Hall.

Becker, Gary S. 1971. The Economics of Discrimination. 2d ed. Chicago: University of Chicago Press.

Beller, Andrea H. 1984. "Trends in Occupational Segregation by Sex and Race, 1960-1981." Pp. 11-26 in Sex Segregation in the Workplace: Trends, Explanations, Remedies, edited by Barbara F. Reskin. Washington, DC: National Academy Press.

Blau, Francine D. and Carol L. Jusenius. 1976. "Economists' Approaches to Sex Segregation on the Labor Market: An Appraisal." Pp. 181-99 in Women and the Workplace: The Implications of Occupational Segregation, edited by Martha Blaxall and Barbara B. Reagan. Chicago: University of Chicago Press.

Boskin, Michael J. 1974. "A Conditional Logit Model of Occupational Choice." Journal of Political Economy 82:389-98.

Breen, Richard. 1994. "Individual Level Models for Mobility Tables and Other CrossClassifications." Sociological Methods \& Research 23:147-73.

Charles, Maria and David B. Grusky. 1995. "Models for Describing the Underlying Structure of Sex Segregation." American Journal of Sociology 100:931-71.

Coleman, James S. 1990. Foundations of Social Theory. Cambridge, MA: The Belknap Press of Harvard University Press.

Eccles, Jacquelynne S. 1987. "Gender Roles and Women's Achievement-Related Decisions." Psychology of Women Quarterly 11:135-72.

Feather, N. T. and John A. Said. 1983. "Preference for Occupations in Relation to Masculinity, Femininity, and Gender." British Journal of Social Psychology 22:113-27.

Gaeddert, William P., Arnold Kahn, Rita L. Frevert, and Ralph Shirley. 1981. "Role Model Choice: Who Do Women Say Their Models Are?" Presented at the 53d annual meeting of the Midwestern Psychological Association, May, Detroit, MI.

Gambetta, Diego. 1987. Were They Pushed or Did They Jump?: Individual Decision Mechanisms in Education. Cambridge, UK: Cambridge University Press.

Hauser, Robert M., Shu Ling Tsai, and William H. Sewell. 1983. "A Model of Stratification With Response Error in Social and Psychological Variables." Sociology of Education 56:20-46.

Heilman, Madeline E. 1979. "High School Students' Occupational Interest as a Function of Projected Sex Ratios in Male-Dominated Occupations." Journal of Applied Psychology 64:275-79.

Herzog, A. Regula. 1982. "High School Seniors' Occupational Plans and Values: Trends in Sex Differences 1976 Through 1980." Sociology of Education 55:1-13.

Hout, Michael. 1988. "More Universalism, Less Structural Mobility: The American Occupational Structure in the 1980s." American Journal of Sociology 93:1358-1400.

Jacobs, Jerry A. 1989. Revolving Doors: Sex Segregation and Women's Careers. Stanford, CA: Stanford University Press.

Kohlberg, Lawrence. 1966. "A Cognitive-Developmental Analysis of Children's Sex-Role Concepts and Attitudes." Pp. 82-171 in The Development of Sex Differences, edited by Eleanor E. Maccoby. Stanford, CA: Stanford University Press.

Laska, Shirley Bradway and Michael Micklin. 1979. "The Knowledge Dimension of Occupational Socialization: Role Models and Their Social Influence." Youth and Society 10:360-78. 
Laws, Judith Long. 1976. "Work Aspiration of Women: False Leads and New Starts." Pp. 33-49 in Women and the Workplace: The Implications of Occupational Segregation, edited by Martha Blaxall and Barbara B. Reagan. Chicago: University of Chicago Press.

Macke, Anne S. and William R. Morgan. 1978. "Maternal Employment, Race, and Work Orientation of High School Girls." Social Forces 57:187-204.

Manski, Charles F. 1990. "The Use of Intentions Data to Predict Behavior: A Best-Case Analysis." Journal of the American Statistical Association 85:934-40.

_. 1993. "Adolescent Econometricians: How Do Youth Infer the Returns to Schooling?" Pp. 43-57 in Studies of Supply and Demand in Higher Education, edited by Charles T. Clotfelter and Michael Rothschild. Chicago: University of Chicago Press.

Marini, Margaret M. and Mary C. Brinton. 1984. "Sex Typing in Occupational Socialization." Pp. 192-232 in Sex Segregation in the Workplace: Trends, Explanations, Remedies, edited by Barbara F. Reskin. Washington, DC: National Academy Press.

Marini, Margaret M. and Ellen Greenberger. 1978. "Sex Differences in Occupational Aspirations and Expectations." Sociology of Work and Occupations 5:147-78.

McFadden, Daniel. 1974. "Conditional Logit Analysis of Qualitative Choice Behavior." Pp. 10542 in Frontiers in Econometrics, edited by Paul Zaremka. New York: Academic Press.

Merton, Robert K. 1968. Social Theory and Social Structure. New York: Free Press.

Perry, David G. and Kay Bussey. 1979. "The Social Learning Theory of Sex Differences: Imitation Is Alive and Well." Journal of Personality and Social Psychology 37:1699-712.

Polachek, Solomon W. 1979. "Occupational Segregation Among Women: Theory, Evidence, and a Prognosis." Pp. 137-57 in Women in the Labor Market, edited by Cynthia B. Lloyd, Emily S. Andrews, and Curtis L. Gilroy. New York: Columbia University Press.

1981. "Occupational Self-Selection: A Human Capital Approach to Sex Differences in Occupational Structure." Review of Economics and Statistics 63:60-69.

Raftery, Adrian E. 1986. "Choosing Models for Cross-Classifications (Comment on Grusky and Hauser)." American Sociological Review 51:145-46.

Rytina, Nancy F. and Suzanne M. Bianchi. 1984. "Occupational Reclassification and Changes in Distribution by Gender." Monthly Labor Review 107:11-17.

Schwarz, Gideon. 1978. "Estimating the Dimension of a Model." The Annals of Statistics 6:461-64.

Seater, Barbara B. and Cecilia L. Ridgeway. 1976. "Role Models, Significant Others, and the Importance of Male Influence on College Women." Sociological Symposium 15:49-64.

Sewell, William H., Archibald O. Haller, and Alejandro Portes. 1969. "The Educational and Early Occupational Attainment Process." American Sociological Review 34:82-92.

Sewell, William H. and Robert M. Hauser. 1975. Education, Occupations, and Earnings: Achievement in the Early Career. New York: Academic Press.

Smith, Walter S. and Thomas O. Erb. 1986. "Effect of Women Science Career Role Models on Early Adolescents' Attitudes Toward Scientists and Women in Science." Journal of Research in Science Teaching 23:667-76.

Stake, Jayne E. and Charles R. Granger. 1978. "Same-Sex and Opposite-Sex Teacher Model Influences on Science Career Commitment Among High School Students." Journal of Educational Psychology 70:180-86.

Stouffer, Samuel A., Edward A. Suchman, Leland C. DeVinney, Shirley A. Star, and Robin M. Williams, Jr. 1949. The American Soldier: Adjustment During Army Life. New York: John Wiley.

U.S. Bureau of the Census. 1973. Occupational Characteristics. Washington, DC: U.S. Government Printing Office. 
Walker, Jon E. 1981. "The Social Context of Modeling." Social Behavior and Personality 9:129-37.

Yamaguchi, Kazuo. 1983. "The Structure of Intergenerational Occupational Mobility: Generality and Specificity in Resources, Channels, and Barriers." American Journal of Sociology 88:718-45.

Zellner, Harriet. 1975. "The Determinants of Occupational Segregation." Pp. 125-45 in Sex, Discrimination, and the Division of Labor, edited by Cynthia B. Lloyd. New York: Columbia University Press.

Yu Xie is John Stephenson Perrin Professor of Sociology in the Department of Sociology and a research scientist at the Population Studies Center and the Institute for Social Research, University of Michigan. His main areas of interest are social stratification, demography, statistical methods, and sociology of science. He is currently completing a project in collaboration with Kimberlee Shauman that studies the recruitment and retention of female scientists.

Kimberlee A. Shauman is an assistant professor of sociology at the University of California, Davis. Her main areas of interest are social stratification, demography, family and kinship, sociology of education, and methodology. 